\title{
Effect of Overlap Orientation on Fatigue Behavior in Friction Stir Linear Welds of Magnesium Alloy Sheets.
}

\author{
J.F.C Moraes ${ }^{1}$, R.I. Rodriguez ${ }^{1}$, J.B. Jordon ${ }^{1 *}$, X. $\mathrm{Su}^{2}$
}

In this work, we investigate the effect of sheet stacking orientation on fatigue behavior in friction stir linear welding of AZ31 Mg alloy. It is well known that during friction stir welding, that the advancing and retreating flow of the material generated by the tool creates asymmetrical weld features resulting is anisotropic mechanical behavior. As such, friction stir welding of overlap joints was carried out on $2 \mathrm{~mm}$ thick sheets, where the orientation of the pull direction of the coupon was varied with respect to the tool rotation direction. Subsequently experimental fatigue tests were performed to evaluate this effect of the sheet stacking orientation on cyclic behavior. The fatigue results showed that the overlap joints loaded on the retreating side exhibited superior performance compared to the advancing side. Post-mortem analysis coupled with finite element results suggest that the geometrical shape of the faying surface produced by the advancing and retreating material flow largely determines the number of cycles to failure in these friction stir linear welded overlap joints. 


\section{Introduction}

Recently, there has been renewed interest in reducing the weight of vehicles in the automotive industry in order to meet the stringent fuel and green house gas emissions standards. One way to achieve this goal is lightweighting the designs through the use of materials with enhanced strength-to-weight ratios [1]. For example, materials such as Al and $\mathrm{Mg}$ alloys, which are known to have high strength-to-weight ratios, are seeing increased use in the body-in-white production. In fact, the employment of lightweight materials, like $\mathrm{Mg}$ alloys, can drastically reduce vehicle weight while maintaining satisfactory structural performance. However, traditional welding techniques, such as resistance spot welding (RSW), which is widely used to join traditional metals like steels, are difficult to implement for joining magnesium alloys [1,2]. This difficulty is mainly due to the high electrical and thermal conductivity [3] characteristics of Mg alloys, which results in high electrical currents and thus can produce poor weld quality. While many alternative joining techniques including fasteners for $\mathrm{Mg}$ alloys exist, friction stir welding (FSW) is ideally suited for joining Mg alloys [4]. FSW is a solid-state process which limits temperatures below the melting point of the material and thus mostly eliminates or significantly reduces problems such as solidification, formation of second phases, porosity, embrittlement and cracking [5]. Moreover, the relatively low temperature at which the process occurs enables the FSW joint to achieve lower distortion and residual stresses [5] compared to fusion welding.

In automotive manufacturing, the overlap is a commonly used joint configuration. In friction stir linear welding (FSLW), which is a variant of FSW, two sheets can be assembled in an overlap configuration, as shown in Fig. 1. In this welding configuration, 
a rotating tool is plunged into the two materials at a predetermined depth, having the tool shoulder in contact with the top sheet as the tool transverses along the welding segment and the lap linear weld is completed when the tool is retracted [6]. Due to the material flow and the tool's direction of travel, two distinctive weld features are produced in overlap welding: the advancing side; and the retreading side. The advancing side (AS) is the side of the tool where the point velocities are faster (rotation plus translation), whereas the retreating side (RS) is the side of the tool where the pin velocities are slower (rotation minus translation).

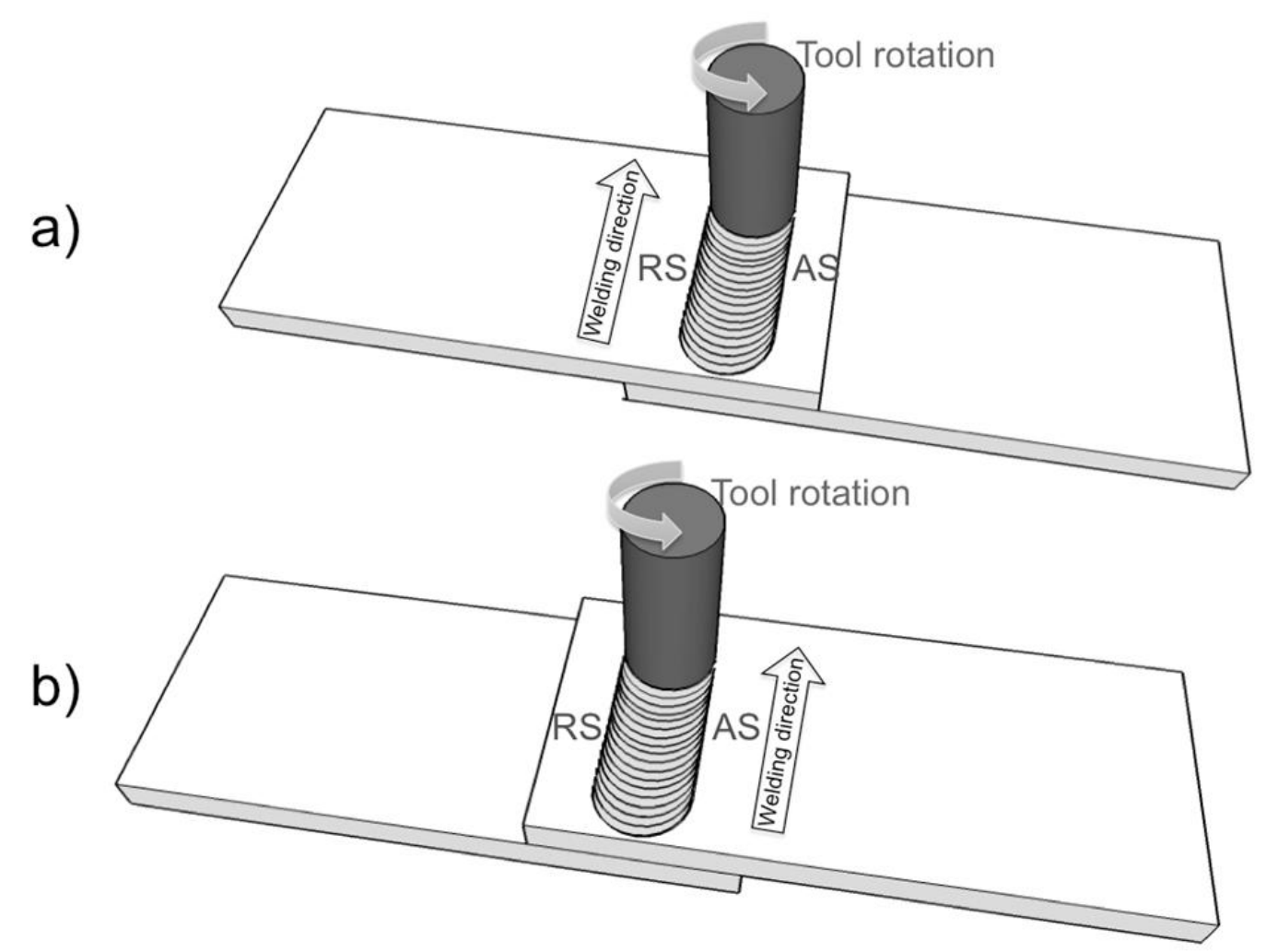

Fig. 1- Coupon layout of friction stir lap welding; a) retreating side, b) advancing side 
In FSLW, the faying surface (surfaces in contact in the joint) of the AS usually remains exterior to the weld nugget and points upwards along the weld nugget boundary [7]. On the other hand, the RS curves up and terminates in the nugget. Since the AS side of the weld takes on a hook-like form, it is typically referred to as the hooking defect; whereas, the RS is known as cold lap defect [7]. It is known that these macro features depend on a combination of tool geometry and welding parameters. Furthermore, it has also been established that these features affect the weld strength and decrease the joint load capacity and/or influence crack nucleation and propagation [8]. As the formation of these macro features depends on the heat generated from the friction between the tool and the pieces to be joined, and material flow during the FSW process, characteristics of FSLW highly depend on tool geometry [6]-[10]. For example, Yang et al. [6] studied different tool geometries and process conditions and their influence on shear strength of AZ31 Mg alloy friction stir lap welds. One of the key results of their research was that a higher tensile load is reached when loading the top sheet of the lap joint configuration on the RS versus loading on the AS. A similar study by Yuan et al.[8] evaluated the effect of different tool designs and weld variables on shear strength in FSLW lap joints of AZ31 $\mathrm{Mg}$ alloy. In their study, they found that the RS of the joint achieved higher loads compared to the AS with the same process parameters. However, they did not explore the effect of RS and AS configuration on fatigue behaviors.

While there exists a few published studies focused on the effect of welding parameters on the static strength of the FSLW in Mg alloys, to the best of the authors knowledge, the effect of sheet stacking orientation on fatigue performance has not been elucidated. As such, the objective of this paper is to quantify the effects of stacking 
orientation on fatigue characteristics of AZ31 Mg alloy joined by FSLW through both experimental and numerical approaches.

\section{Materials and experiments}

For this study, commercial grade $2 \mathrm{~mm}$ thick AZ31 $\mathrm{Mg}$ alloy sheets were employed, which contained a nominal chemical composition of $\mathrm{Mg}-3.0 \%$ wt $\mathrm{Al}-1.0 \%$ wt $\mathrm{Zn}$, with a base material yield strength of $250 \mathrm{MPa}$, and an ultimate strength of $342 \mathrm{MPa}$ [11]. For welding purposes, the sheets were cut to a width of $75 \mathrm{~mm}$ and length of approximately $1,500 \mathrm{~mm}$. The plates were assembled in an overlap configuration and welded at a tool rotational speed of $2000 \mathrm{rpm}$ and a travel speed of $4.6 \mathrm{~mm} \mathrm{~s}^{-1}$. A FSW tool having a concave scroll shoulder with $13 \mathrm{~mm}$ diameter, a $3.5 \mathrm{~mm}$ long triflat threaded pin, a $4.7 \mathrm{~mm}$ pin tip diameter, and $6.0 \mathrm{~mm}$ pin root was used to weld the lapshear samples. As shown in Figs. 1a and 1b, for the same traveling direction and rotation of the tool, the side of the weld to be loaded is defined according to the orientation of the sheets relative to the pull direction. Two sets of FSLW were created in an overlap configuration. The only difference between the two sets of coupons is the overlap orientation (i.e. the orientation of the top and bottom sheets in order to have the advancing or retreating side on the free edge of the top sheet). A schematic drawing of the coupons is shown in Fig. 2a. After welding was completed, the FSLW overlap plates were cut into $30 \mathrm{~mm}$ wide by $120 \mathrm{~mm}$ long coupons for mechanical testing purposes. Figure $2 \mathrm{~b}$ shows the configuration for the coupons oriented to the RS and AS.

A MTS servo-hydraulic was used to perform lap shear tensile test (quasi-static) for each sheet stacking frame configuration in order to obtain a representative average 
ultimate load carried by the joint. Four coupons were tested per configuration and a gripto-grip distance of $60 \mathrm{~mm}$, at an actuator speed of $1 \mathrm{~mm} \mathrm{~min}^{-1}$ was used during tensile testing. For fatigue testing, the coupons were tested with the same grip-to-grip distance in an MTS servo-hydraulic with a $2.2 \mathrm{kN}$ load cell, under load control condition with a sinusoidal waveform at load ratio $\mathrm{R}=0.1$ and a frequency of $20 \mathrm{~Hz}$. Shims were used in both the quasi-static and fatigue tests in order to avoid additional bending moments and loads on the test samples.

a)
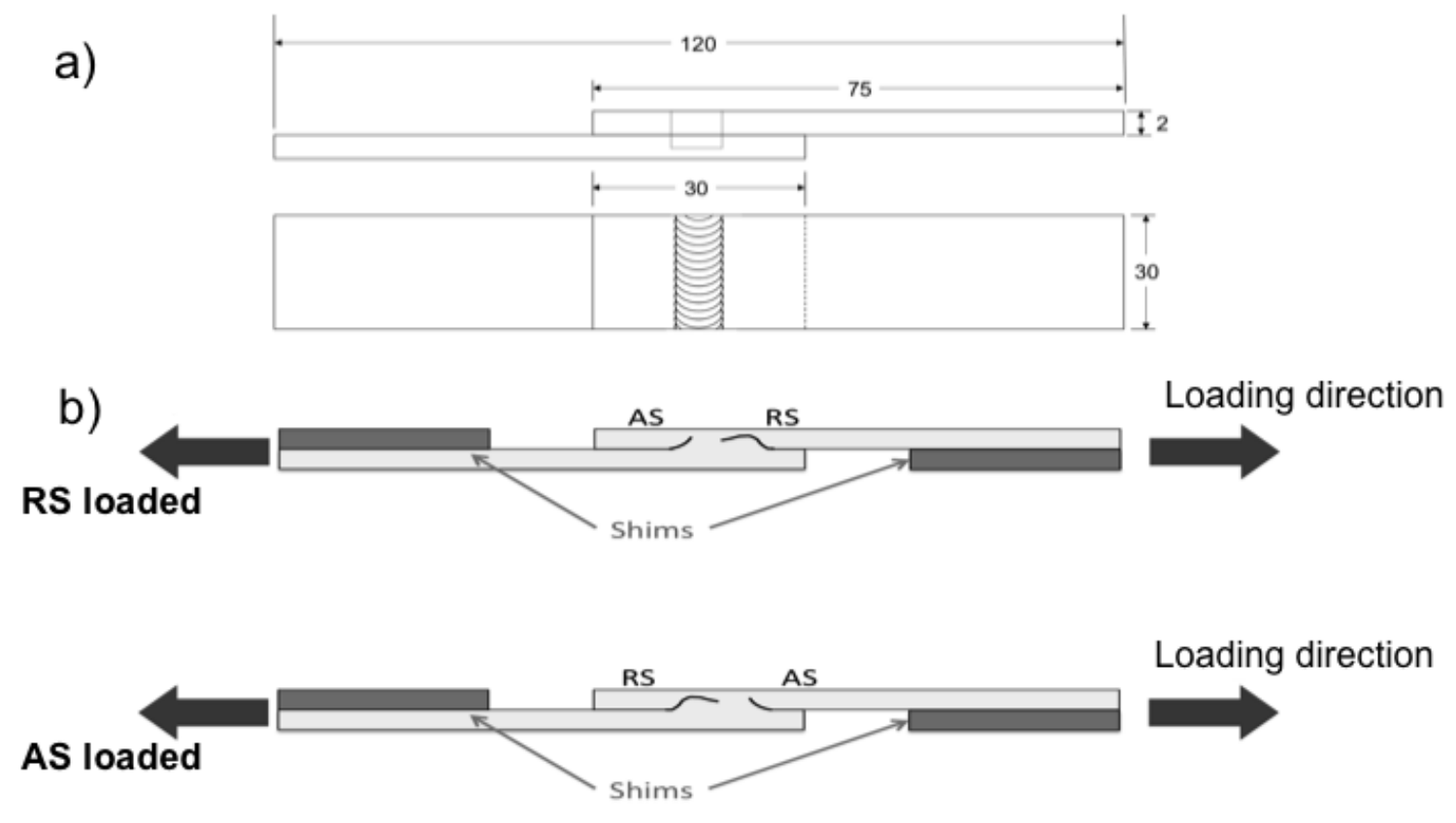

Fig. 2- a) Configuration of the friction stir linear welded (FSLW) lap-shear coupon. b) Schematic of loading configurations: retreating side (RS) and advancing side (AS). Dimensions are in millimeters.

In addition to mechanical testing, analysis of the weld microstructure and postmortem analysis were conducted. Mechanically untested and tested coupons were sectioned parallel to the loading direction, cold mounted in epoxy, ground, and polished. The final polishing was done on a neoprene pad with alumina 0.05 micron in glycol 
slurry. In order to characterize the microstructure, the mounted coupons were etched using a solution composed of $4.2 \mathrm{~g}$ picric acid, $10 \mathrm{ml}$ acetic acid, $10 \mathrm{ml} \mathrm{H}_{2} \mathrm{O}$ and $70 \mathrm{ml}$ ethanol [12], [13]. An optical digital microscope Keyence VHX-1000 was used to evaluate size and shape of the weld features, the effective sheet thickness, and the transverse crack propagation under different loading conditions. Microtexture characterization of the FSLW coupons was performed using a JEOL 7000 scanning electron microscope (SEM) equipped with a detector for electron backscatter diffraction (EBSD). All samples were electro-polished at $3 \mathrm{~V}$ for 20 seconds using $\mathrm{H}_{3} \mathrm{PO}_{4}$ diluted in ethanol (3:5 ratio). EBSD analysis was conducted using $20 \mathrm{kV}$ beam voltage in $0.9 \mu \mathrm{m}$ steps. Microtexture data was acquired using the AZTEC software from Oxford Instruments and post-processing was done using the HKL Channel 5 package.

Microhardness measurements were conducted on the cross section of the top and bottom sheets with increments of approximately $0.5 \mathrm{~mm}$, using a Wilson hardness testing machine. A load of $100 \mathrm{~g}$ with a dwell time of 5 seconds was applied in order to obtain the Vickers hardness (HV) across the weld nugget. For crack nucleation and propagation analysis, fractured surfaces of the fatigue tested coupons were examined in the Jeol 7000 SEM.

\section{Results and discussion}

\subsection{Geometrical features}

A representative cross-section of a FSLW coupon is presented in Fig. 3. As noted earlier, the faying surface on the advancing side (AS) usually exhibits the shape of a hook and curves upwards along the nugget (is also the stir zone in the FSLW) periphery. On the opposite side of the weld, the faying surface on the retreating side (RS) extends 
through the weld nugget towards the AS, where this feature is generally referred as coldlap feature [8]. These distinct features are a result of trapped oxide films that are on the surface of the sheets prior to welding. These trapped oxide film features depend on relative velocities between the tool and work material. The material in front of the rotating tool is pushed upward due to the tool tilt angle. The amount of material being driven upward on the leading side flows around the pin in the rotation direction [14][16], resulting in a hook feature that points upwards (Fig. 3b). As this material flow decelerates on the trailing side, it accumulates resulting in flow away from the tool pin [15], thus leading to the downward pointing lap-feature, as shown in Fig 3c. Figure. 3d shows the peak height of cold-lap feature.

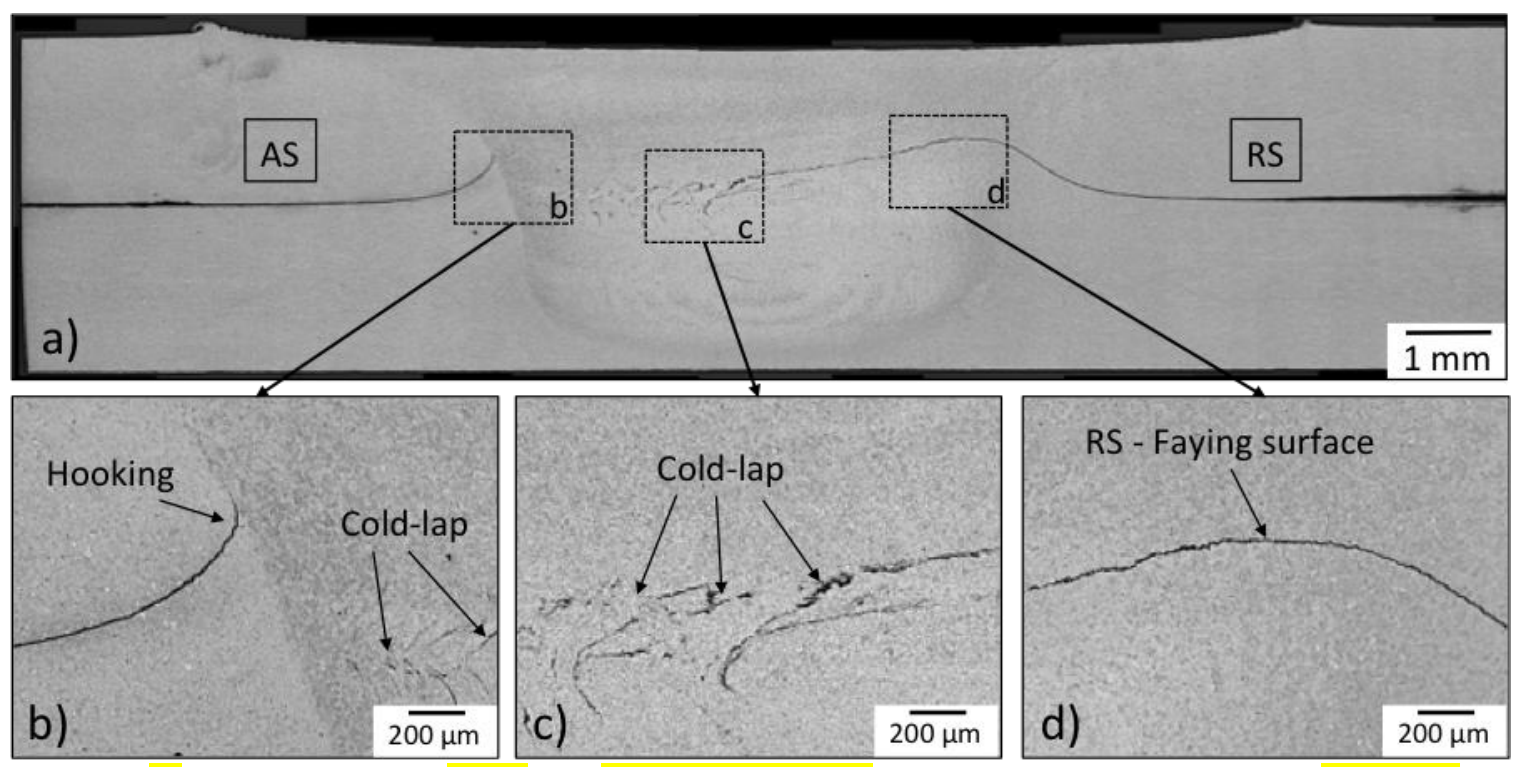

Fig. 3- a) Cross-section view of a representative friction stir linear weld (FSLW) in overlap configuration where AS is the advancing side and RS is the retreating side. Magnified views of the b) hooking feature of the AS, c) cold-lap features in the stir zone, d) and in the RS.

\subsection{Microstructure and Hardness}

Figure 4 shows the results of the microstructure characterization by EBSD measurements. In particular, inverse pole figures (IPF) illustrate the grain orientation, as 
well as grain size distribution of the FSLW coupon. Figure 4a shows the locations of the EBSD measurements. For both the base material (BM) and the stir zone (SZ), a strong texture can be observed in Fig. 4b. This strong texture is due to the rolling process of the $\mathrm{Mg}$ sheet material in the $\mathrm{BM}$ and the large shear deformation caused by the tool in the SZ. Lastly, Figure $4 \mathrm{c}$ shows the grain size distribution comparison between the BZ and the SZ, where the average grain size of SZ was only slightly finer than the BZ.

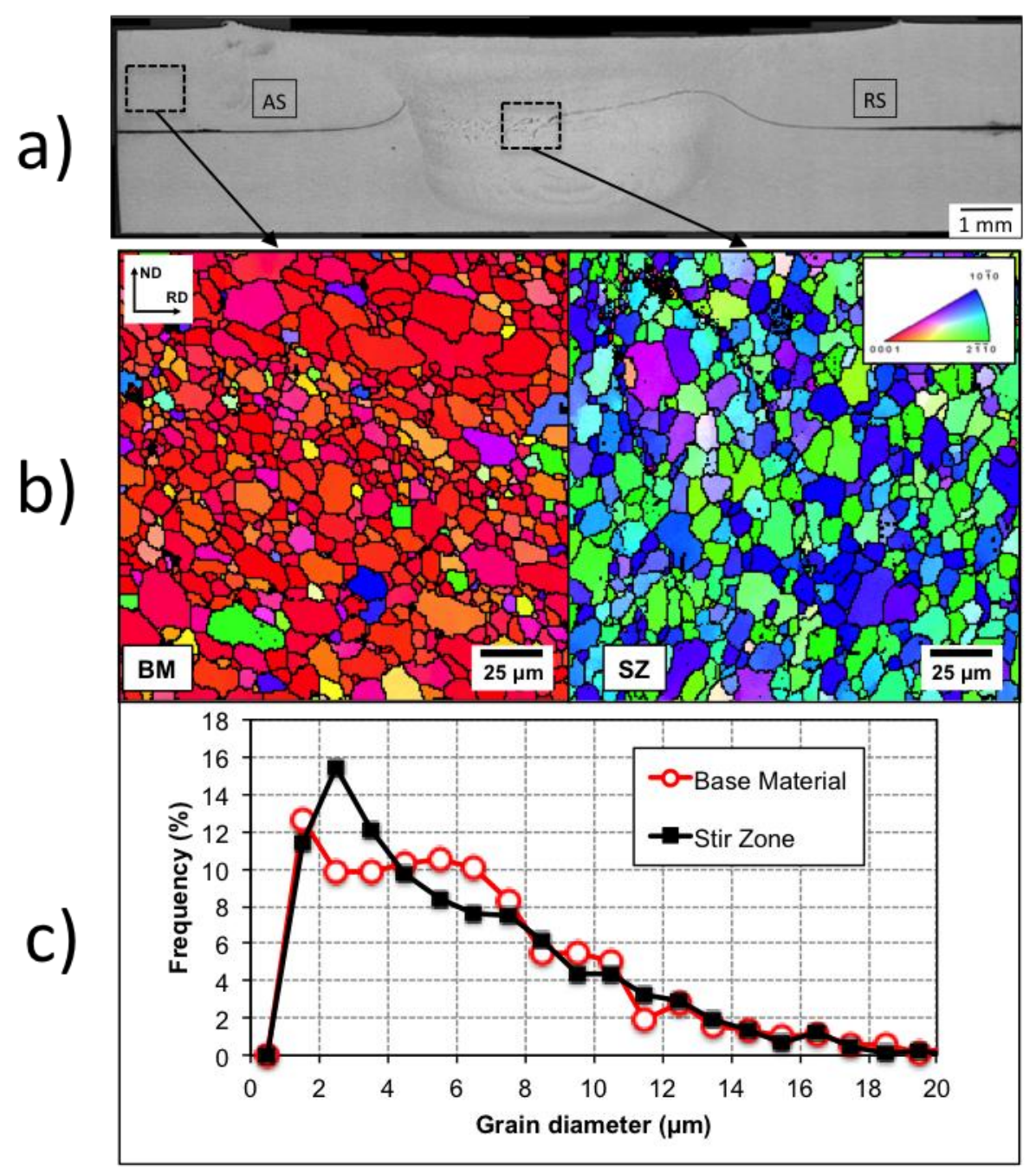

Fig. 4- Microstructure features: EBSD analysis of the base material and stir zone. a) Joint cross-section. b) Inverse Pole figures of BM (base material) and SZ (stir zone). c) Grain size distribution plot. 
Figure 5 shows a representative hardness profile of the FSLW coupons. The horizontal axis represents the distance from the center of the nugget of the weld in $\mathrm{mm}$. The vertical axis represents the measured Vickers (HV) hardness value. As shown in Fig. 5, the center of weld nugget exhibited higher hardness compared to outer edges of the SZ. As shown in Fig. 5, hardness values change significantly across the weld. However, the hardness profile of the FSLW exhibited symmetry from the center of the weld outward, showing similar hardness values for the AS and RS sides. Moreover, there was not a significant difference of hardness measurement in the areas where the fatigue cracks initiated in the AS and RS of the weld. This will be discussed later in this paper.

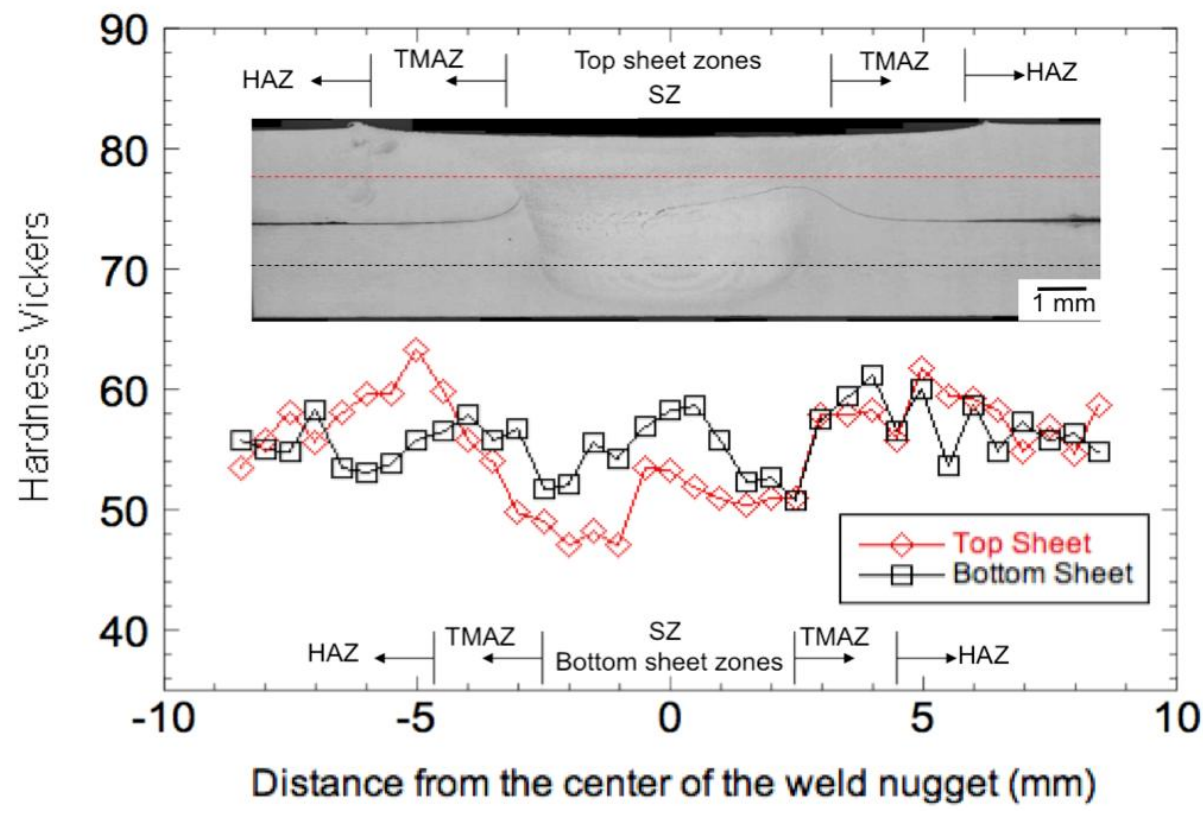

Fig. 5- Microhardness size profile across friction stir linear weld coupon. Hardness of base material: $59.82 \pm 2.69 \mathrm{HV}$.

\subsection{Tensile Behavior}

Tensile tests were conducted to evaluate the joint strength of the AS and RS orientation, where 3 samples were tested in both the AS and RS orientations. It is noted 
that, in a similar study on AZ31 Mg alloy joints, Yuan et al. [8] reported that the RS orientation achieved higher lap-shear strength when compared to the AS produced under the same welding parameters. However, in the current study, the welding parameters are slightly different from the work by Yuan et al.[8], whereas the trend in mechanical behavior of the joint performance in this study was similar. In fact, in this study, the average ultimate load of the RS was approximately $50 \%$ greater than the AS orientation. Representative load-displacement curves under quasi-static lap-shear testing of the RS and AS coupons are shown in Fig. 6.

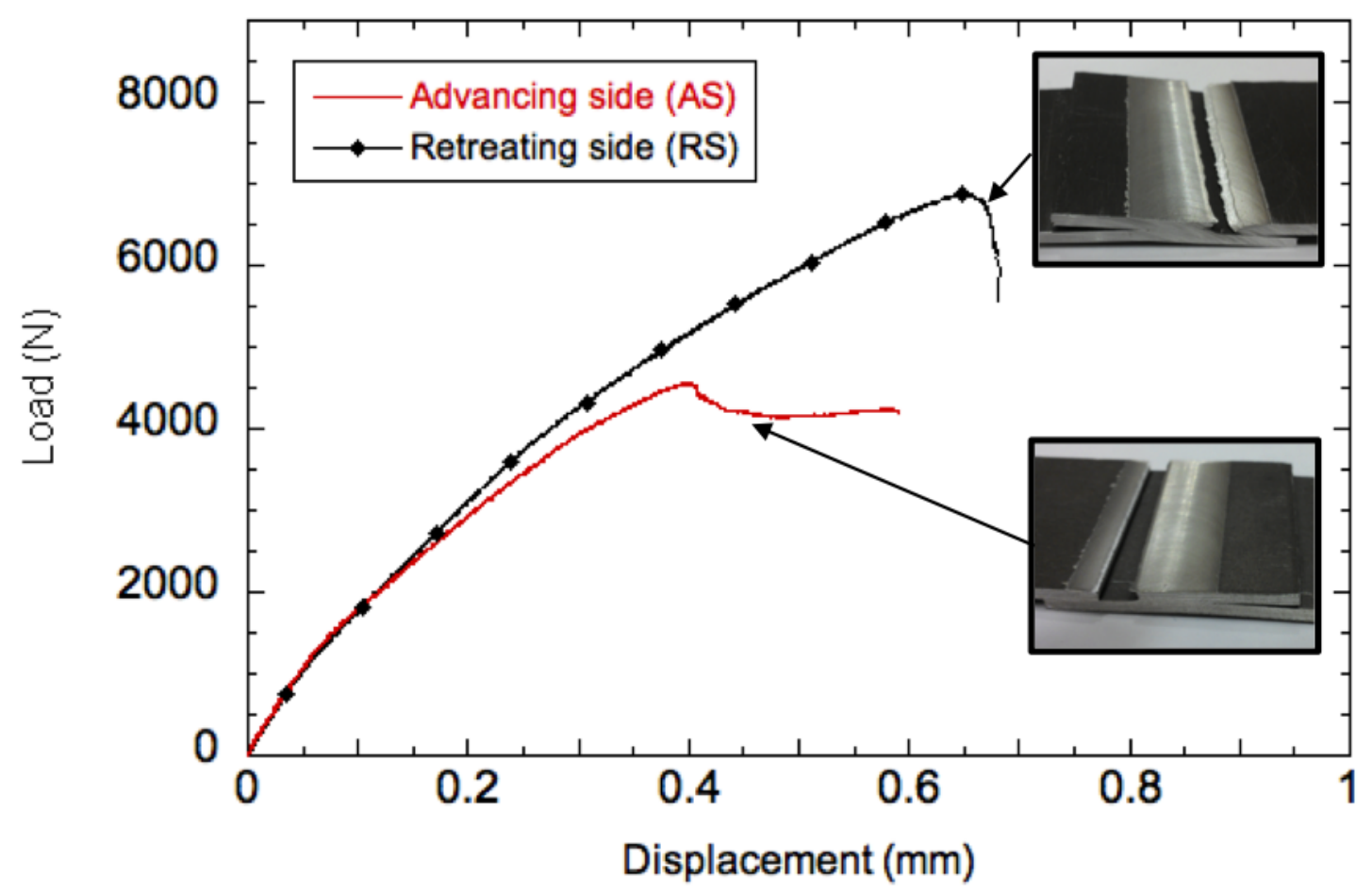

Fig. 6- Representative load versus displacement curves of FSLW lap-shear tests of the retreading side (RS) and advancing side (AS) orientated coupons.

Regarding the fracture behavior of the coupons under tensile loading, representative cross-sections of fractured coupons are shown in Fig. 7. Figures 7a-c show 
optical cross-sectional views of a fractured AS coupon, while Figs. 7d-f show optical cross-sectional views of a fractured RS coupon. The darker areas of the optical images in Figs. $7 \mathrm{~b}$ and $7 \mathrm{e}$ show the twinning distribution due to the large scale deformation under monotonic loading conditions. Figs. $7 \mathrm{c}$ and $7 \mathrm{f}$ show high magnification of the twinning density in detail. Similar results were reported by Yang et al. [6], where this type of failure is due to localization of deformation, indicated by mechanical twins near the fractured surface.
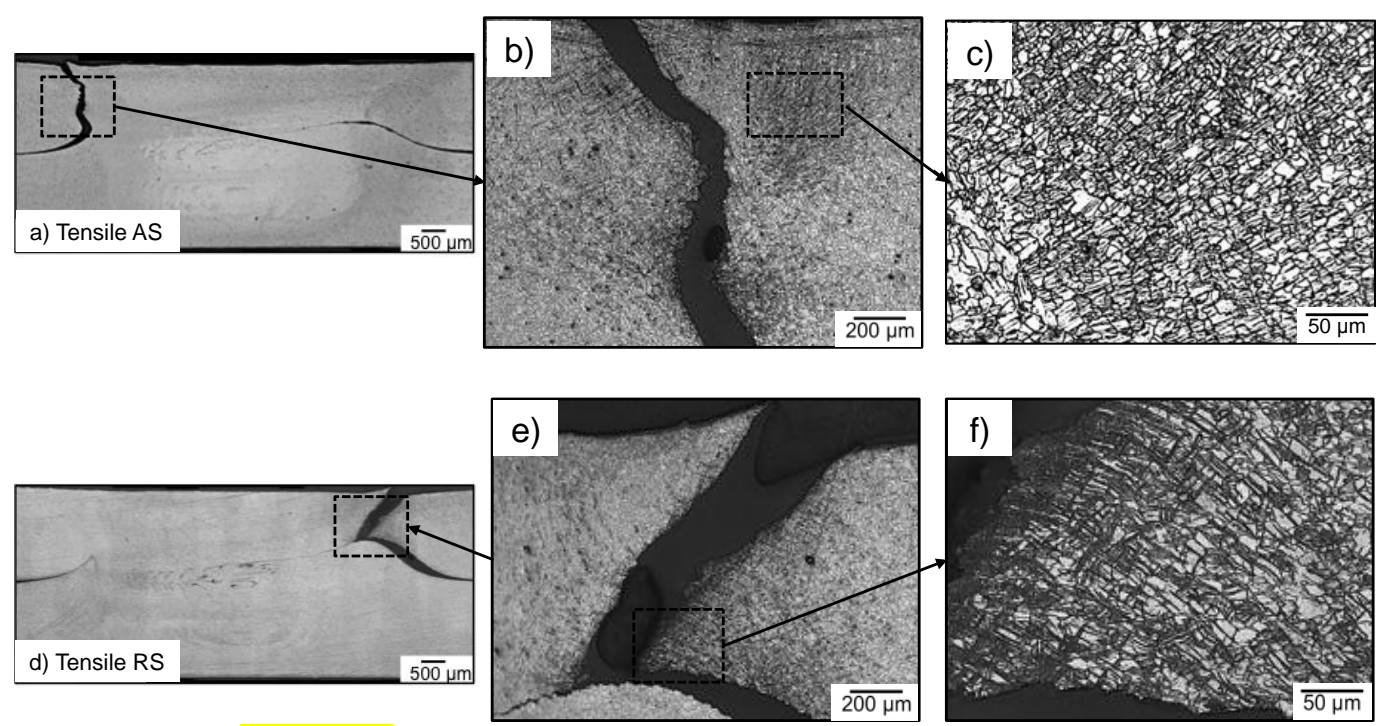

Fig 7- Failed lap-shear coupons loaded on: a) advancing side, d) retreating side. Twinning distribution near the facture: b) advancing side, e) retreating side. Higher magnification of twining in detail: c) advancing side, f) retreating side.

\subsection{Fatigue Behavior}

Figure 8 shows the experimental results of the fatigue tests of the FSLW lap-shear coupons in the RS and AS orientation. In this figure, the vertical axis represents the load range applied to the joint and the horizontal axis is the corresponding number of cycles to failure, where we define failure as the complete separation of the joint. The arrows on the plot indicate run-outs. It can be observed that the RS orientation exhibited superior 
fatigue lifetimes compared to the AS orientation at the same cyclic load. In addition, Fig. 8 indicates a nearly linear offset of the fatigue behavior of the RS as compared to the AS orientation. This result suggests a strong correlation to the ultimate strength of the joint and fatigue behavior, which will be discussed later in the paper.

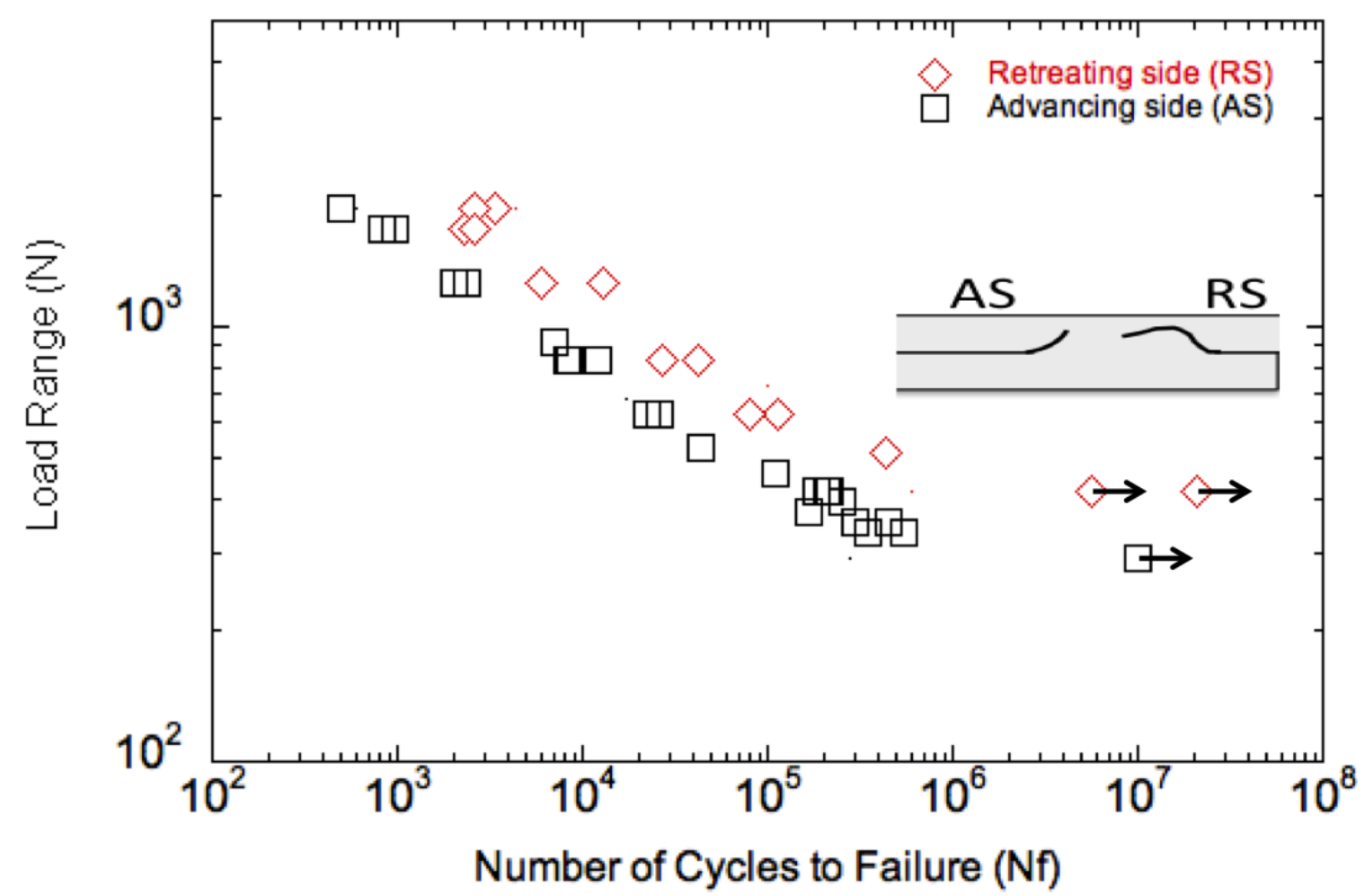

Fig. 8- Experimental results of load range versus the number of cycle to failure of the FSLW lap-shear coupons tested at a load ratio $\mathrm{R}=0.1$

Regarding the fracture behavior of the coupons under fatigue loading, Figs. 9 and 10 show the cross-sections of representative failed coupons. For clarification purposes in this study, we classify the fatigue loading into low cycle fatigue $(<10,000$ cycles $)$ and high cycle fatigue $(>10,000)$ regimes.

The cross-sections of failed coupons in the low cycle fatigue regime are depicted in Fig. 9. The low cycle fatigue failure of the AS is shown in Fig. 9a where failure 
occurred at 503 cycles at a maximum load of 2,069 N. The low cycle fatigue failure of the RS occurred at 2,620 cycles at a maximum load of 2,069 $\mathrm{N}$ as shown in Fig. 9d. In both cases, cracks grew in mode I propagation directly through the stir zone and into the surface of the top sheet as shown in detail in Figs. 9b and 9e. Also, less twinning was observed compared to monotonic loading due to lower severity of plasticity as can be seen in detail in Figs. 9c and 9f .
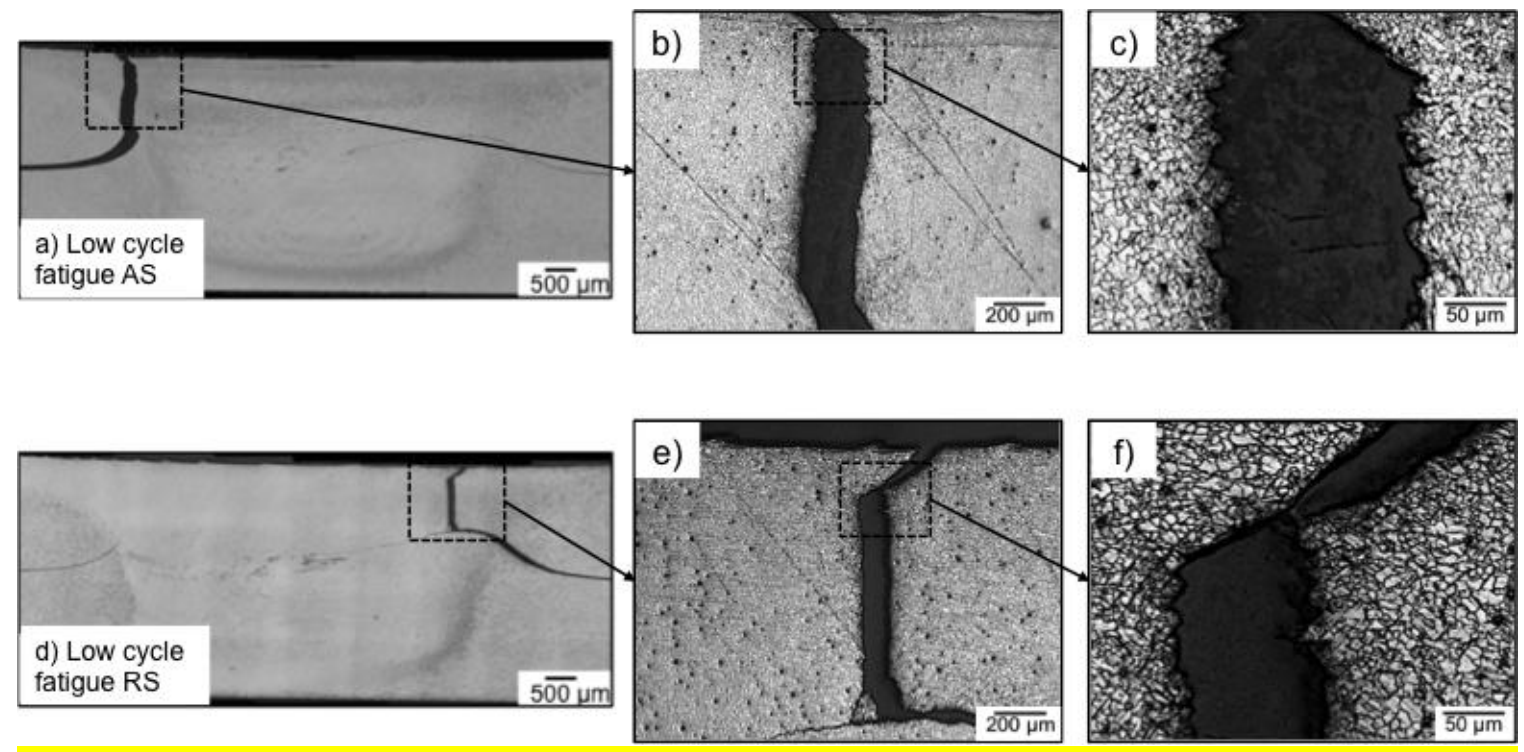

Fig 9- Representative cross-sectional views of fractured low cycle fatigue coupons loaded on: a) advancing side (503 cycles), d) retreating side (2,620 cycles). Magnified view of the crack growth path through the stir zone: b) advancing side: e) retreating side. High magnified view of the crack path near rupture: c) advancing side, f) retreating side. Load ratio was $R=0.1$.

The high cycle fatigue failures are shown in Fig. 10, where failure of the AS presented in Fig. 10a occurred at 353,589 cycles at maximum load of 371 N. Figure 10d shows the failure of the $\mathrm{RS}$ at 437,661 cycles at a maximum load of $570 \mathrm{~N}$. It is important to note that at lower applied amplitudes, the crack propagates through the boundary between the SZ and TMAZ in mixed-mode (I+II) behavior in both conditions, and evidence of twinning was not optically observed as shown in Figs. 10b and 10e. Figures 
$10 \mathrm{c}$ and $10 \mathrm{f}$ show in detail multiple crack propagation directions. Additionally, crack branching was observed that was not observed in the low cycle fatigue samples. This may indicate relatively low residual stresses due to the welding process not having a significant influence on the behavior of the fatigue lives, which is shown in Fig.8.

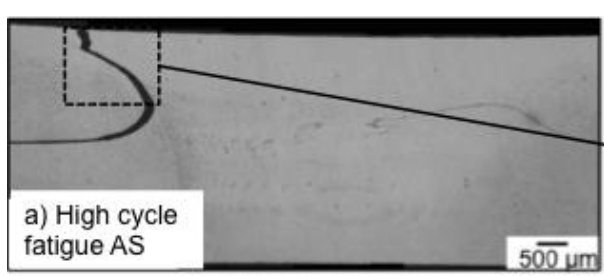

\section{b)}

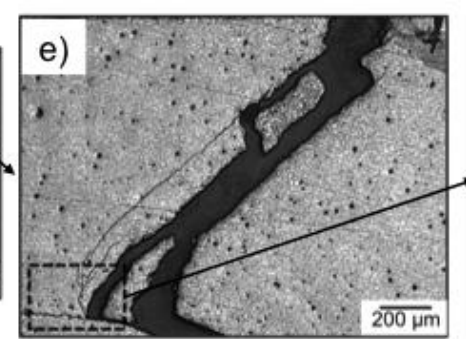

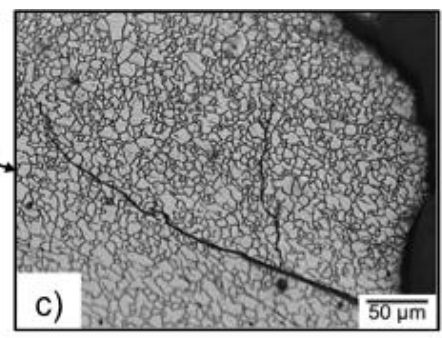

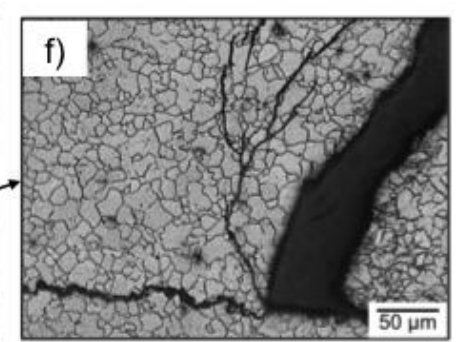

Fig 10- Representative cross-sectional views of fractured high cycle fatigue coupons loaded on: a) advancing side (failure at 353,589 cycles), d) retreating side (failure at 437,661 cycles). Magnified view of crack path that grew between the stir zone and the thermo-mechanically affected zone: b) advancing side: e) retreating side. High magnified view of secondary cracks: c) advancing side, $\mathrm{f}$ ) retreating side. Load ratio was $\mathrm{R}=0.1$ 

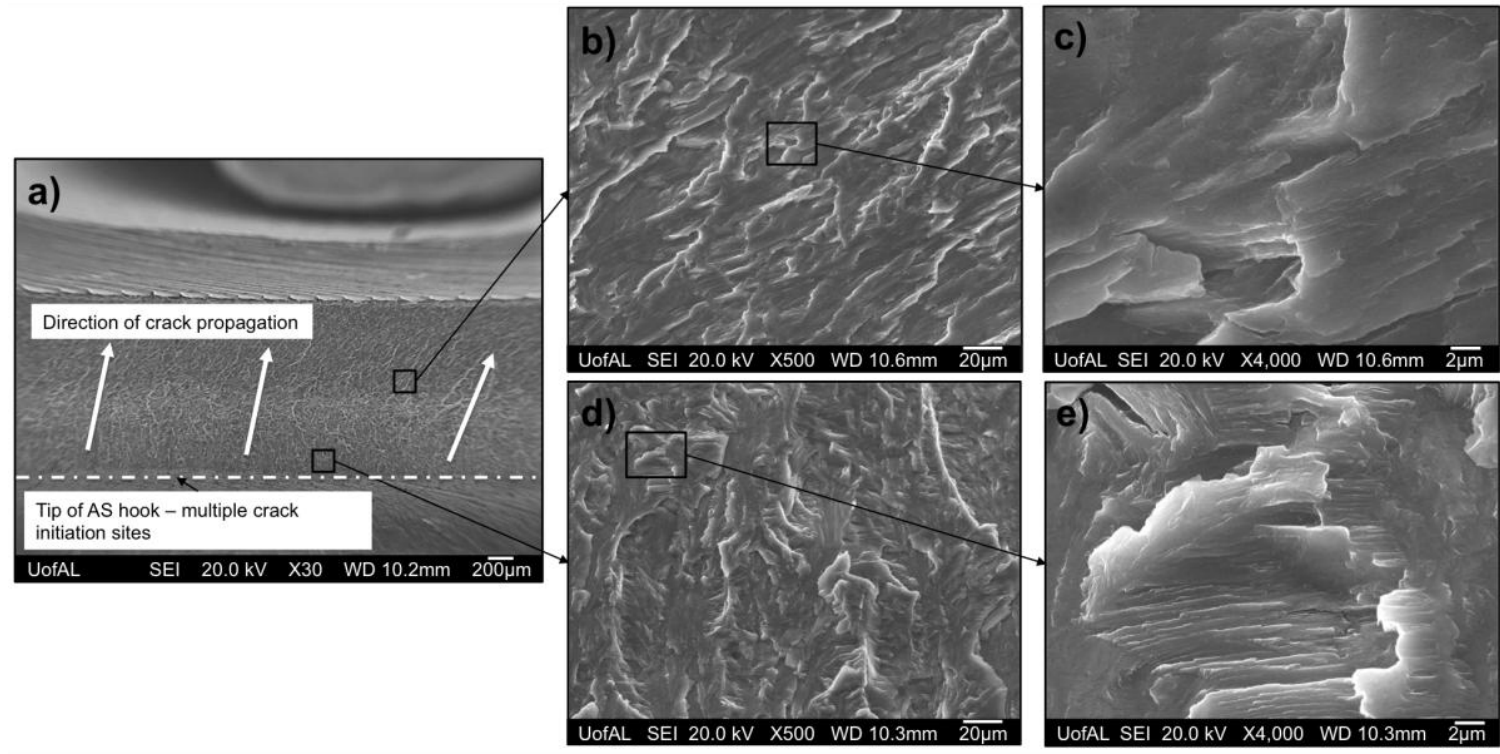

Fig. 11- Representative fracture surface of a) AS, where failure occurred at 43,368, b) fracture surface relatively far from the crack initiation location, c) example of large striation spacing, d) fracture surface near the crack initiation site, e) and example of small striation spacing.

Figures 11 and 12 show SEM images of fatigue fracture surfaces of the AS and RS orientated coupons. Figure 11a shows the AS, where failure occurred at 43,368 cycles at a maximum load of $580 \mathrm{~N}$. The ratchet marks indicate that the cracks initiated at multiple locations across the hook tip, and then grew towards the top surface in the direction indicated by the white arrows. A further evaluation was made by analyzing crack initiation in the areas close to the hook tip (Fig.11d) and steady crack growth regime some distance from the hook tip (Fig. 11b). Also note that the striation spacing is small in areas near to the hook tip as shown in Fig.11e, and larger in areas further from the hook tip as observed in Fig.11c. These results agree with the proposed crack initiation location and crack propagation direction presented previously. 

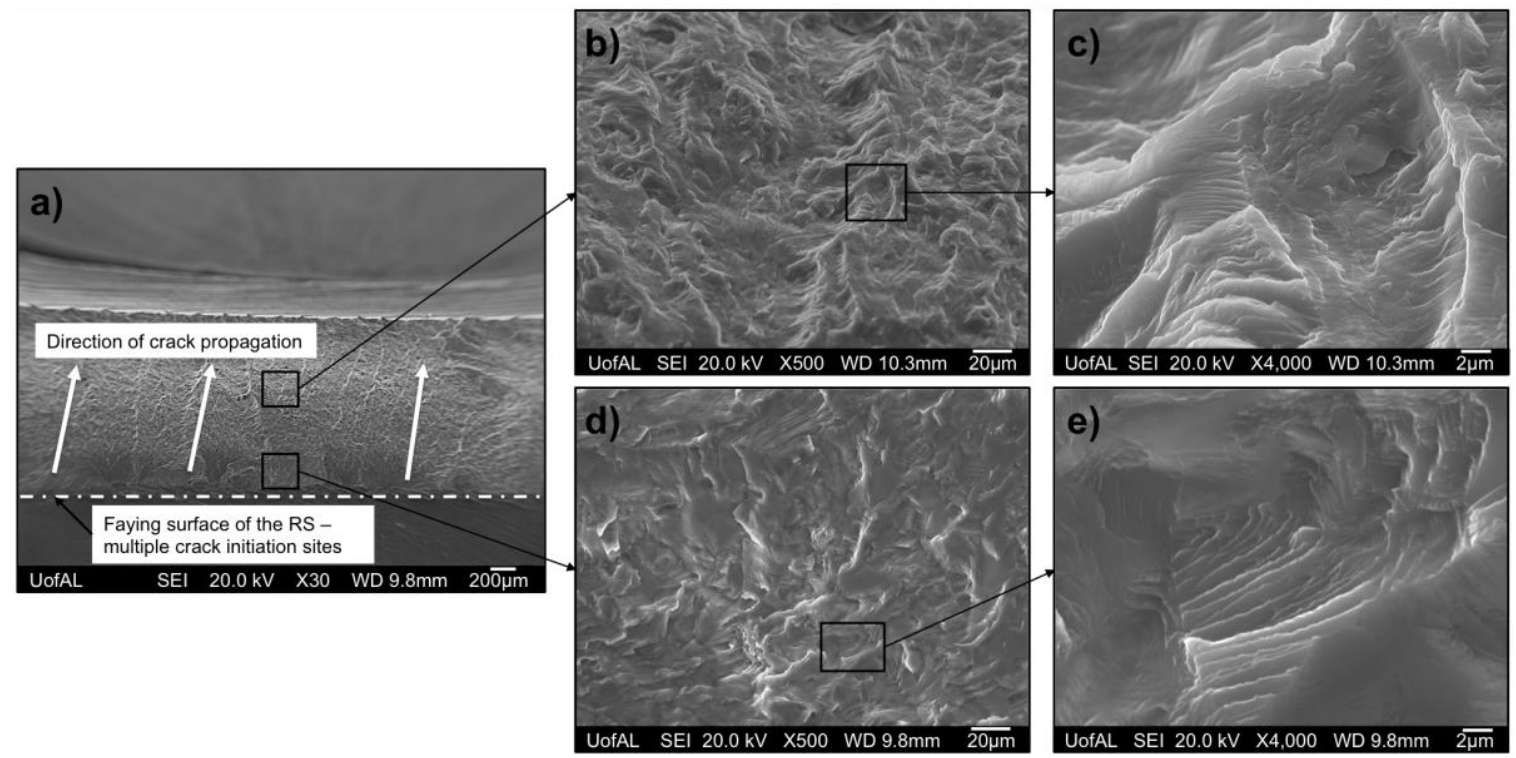

Fig. 12- Representative fracture surface of a) RS, failure at 432,166 cycles, b) fracture surface relatively far from the crack initiation, c) large striation spacing, d) fracture surface near the crack initiation, e) and small striation spacing.

In Fig. 12a, the RS coupon failed at 432,166 cycles at a maximum load of $570 \mathrm{~N}$. Crack nucleation and propagations are very analogous comparing AS and RS, however ratchet marks indicate that multiple crack initiation locations occurred along the faying surface of the RS. The previously mentioned cracks propagated toward the free surface of the top sheet, and are indicated by white arrows in Fig.12a. Figure 12 also shows the analysis of the areas close to the faying surface (Fig.12d) and farther from it (Fig.12b). Similar to the AS coupon, the striation spacing is small in areas close to the faying surface as shown in Fig.12e and larger striation spacing is observed in Fig.12c, it supports the proposed crack initiation location and crack propagation direction presented for the RS. 


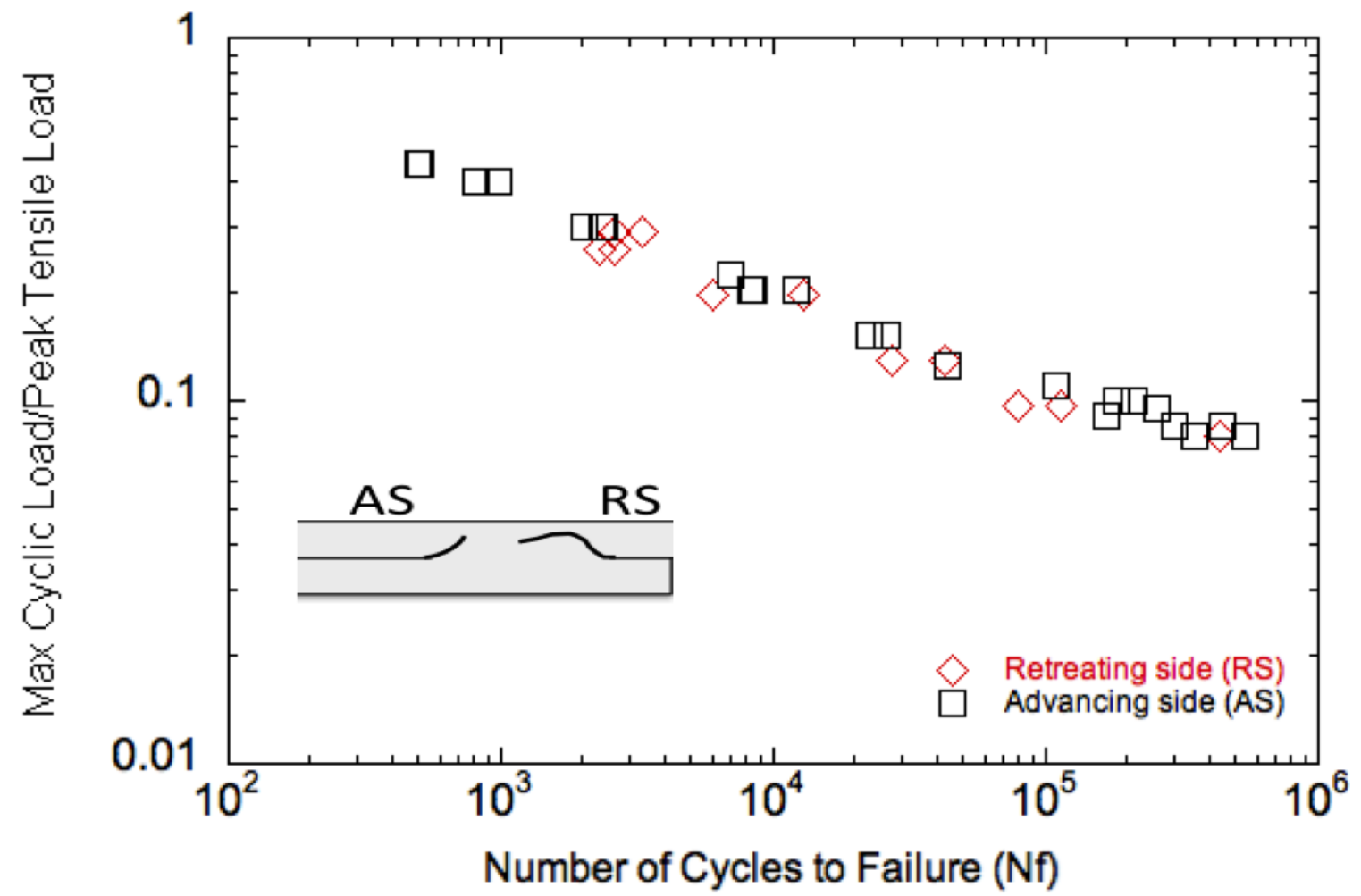

Fig. 13- Experimental results of the maximum cyclic load normalized by the mean peak tensile load obtained from quasi-static tensile results, versus the number of cycle to failure of the coupon at a load ratio of $\mathrm{R}=0.1$.

Since post-mortem analysis of the FSLW coupons show similar failure characteristics, the difference in the number of cycles to failure is likely related to the geometry of the macro features, namely the AS and RS features. Furthermore, as confirmed in this study and elsewhere, the static strength of FSLW joint is also correlated to these macro features. To test the hypothesis that the static and fatigue strengths of the $\mathrm{RS}$ and AS orientation can be related to one another, the fatigue results shown in Fig. 8 were re-plotted by normalizing the applied fatigue load by the corresponding ultimate static lap-shear strength for the RS and AS orientation as shown in Fig. 13. Thus, it can be clearly observed that the normalized curves for AS and RS in Fig. 13 virtually collapsed into a single curve (note that the run-out data points were not shown since 
actual failure did not occur in these coupons). This is significant since it suggests that for the FSLW of a similar Mg alloy, the fatigue difference associated with stacking orientation appears to be correlated directly with static lap-shear strength of the joint. Furthermore, these normalized results also suggest that, during the product development phase, engineers would only need to perform fatigue tests on one of the joint orientations if both the static strengths for both are known. However, more experiments with different welding parameters and additional materials are needed to test this hypothesis.

\subsection{Fatigue Modeling}

To further test the hypothesis that the difference in fatigue behavior in the AS and RS is related to geometrical features of the FSLW, finite element calculations were performed. Since the FSLW coupons have a plane of symmetry, the commercial code FRANC2D was used to calculate the stress intensity factors of the AS and RS features using linear elastic fracture mechanics under plane strain calculations. The material card for AZ31 Mg alloy was defined as elastic and isotropic, with Young's modulus of 45 $\mathrm{GPa}$, poisson ratio of 0.35 , and a thickness of $30 \mathrm{~mm}$. The analyses were performed with the option DIRECT STIFF, which performs a linear elastic stress analysis using a direct elimination (Gauss elimination) solver. First, a monotonic lap-shear tensile pull of the FSLW coupon was performed for both AS and RS configurations with no predefined crack. The elements were defined as second order Q8 quadrilateral elements, with average element dimensions of $0.2 \times 0.2 \mathrm{~mm}$. The results of these calculations showed where the stress raisers would be located in the lap-joint under fatigue loading. Next, an initial crack was created at the location of these peak stresses in order to initiate crack growth. It is important to note that due to the observed hooking and cold-lap features, we 
assumed that fatigue crack incubation stage was negligible. This assumption is a widely accepted for welded joints and in particular is supported by similar fatigue work on friction stir spot welds of the AZ31 Mg alloy $[4,12]$ and dissimilar Mg-Al alloy lapjoints [17]. For the finite element calculations, constant distributed load was applied as a traction force in order to obtain a fatigue curve. The initial crack was defined as noncohesive, with a normal traction-free crack surface starting at the edge, and contact between surfaces of the crack was not defined since they do not interact with each other. The initial crack length was set at $3.59 \times 10^{-3} \mathrm{~mm}$ at 45 degrees from the direction of the applied load, with second order T6 triangular elements around the crack tip region. For clarification purposes, and the initial crack used in the crack growth calculations is shown in Fig. 14a, and a magnified view of the crack tip is shown in Fig.14b.

The crack grew automatically using a predefined crack extension and automatic remeshing functions contained in the FRANC2D solver. Using this option, the crack grew automatically in the maximum hoop stress direction with no pre-defined path by determined the user. In this study, the crack extension was not calculated per cycle but rather the crack length was extended at a predefined increment of $2.54 \times 10^{-2} \mathrm{~mm}$, which was the smallest increment size allowed by FRANC2D. At each step, the new crack extension was created with 2 elements and the stress intensity was calculated as a function of crack length. An example of the final crack extension with the remeshing around the crack as it grew through the AS orientated sample is shown in Fig.14c, where a magnified view of the final crack shown in Fig.14d. The simulation stopped when the crack tip was near the free surface, as shown in Fig.14d. Using the minimum crack extension, a total 43 steps were required for the RS and 45 steps were required for the 
AS. For the RS, the meshing of the initial crack and the crack extension was similar to the AS but is not shown for brevity's sake.
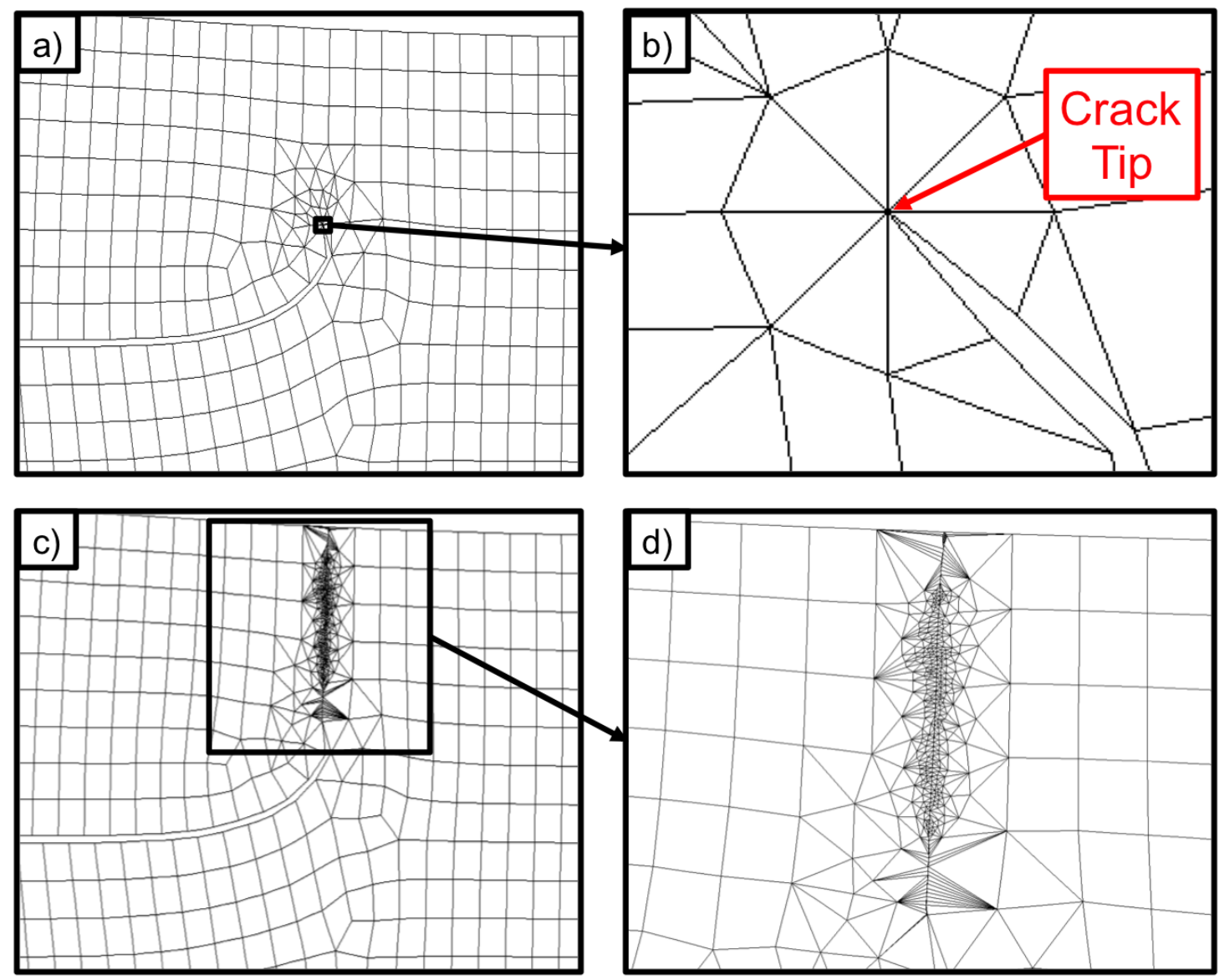

Fig. 14- a) Mesh of the initial crack of advancing side coupon and b) a magnified view of the crack tip. c) Overall view of the mesh of the final crack, and d) a magnified view of the propagated crack.

For clarity purposes, the overall lap-shear coupon with the boundary conditions of the simulations are shown in Fig. 15a for the AS orientation and Fig. 15d for the RS orientation. All nodes were constrained on the out of plane direction ( $\mathrm{z}$ axis) due the model definition (2-D, plane strain). The left end of the virtual coupon was constrained in all directions. The opposite end was constrained on the vertical direction (y axis) and the load was applied on the horizontal direction (x axis). The resulting deformed mesh after crack growth simulations is shown in Figs. $15 \mathrm{~b}$ and $15 \mathrm{e}$, where the results were visually 
compared to the cross-section of the experimental fractured coupons of AS and RS configurations, respectively. It can be observed that the predicted crack paths visually agree well with the fractured low cycle fatigue samples. We note that for the high cycle fatigue samples, the fatigue crack propagated along the interface of the SZ and the TMAZ as shown in Fig. 10. Thus we acknowledge that the simulation results did not capture this mixed-mode fracture path. However, we note as shown in Fig. 10, the mixedmode fracture was observed similar in both the AS and RS, and thus any error this contributes to the fatigue calculations is identically applied to both orientations.

a)

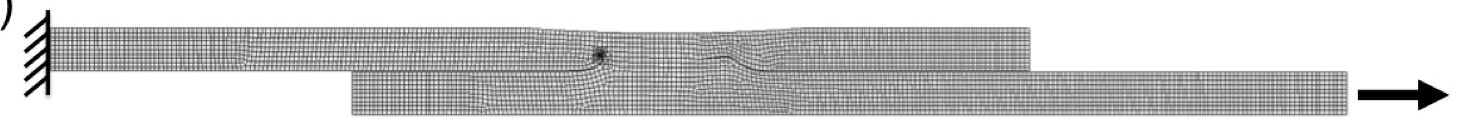

b)

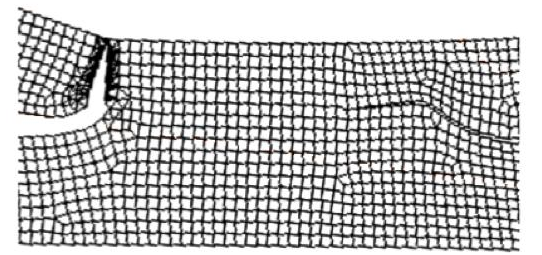

c)

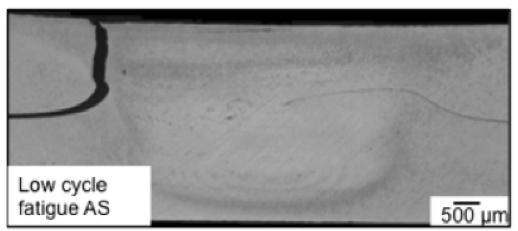

d)

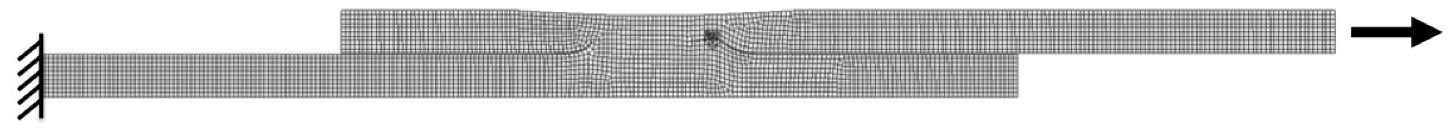

e)

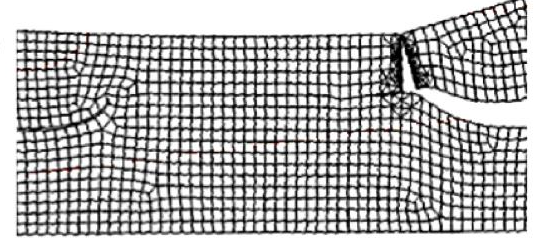

f)

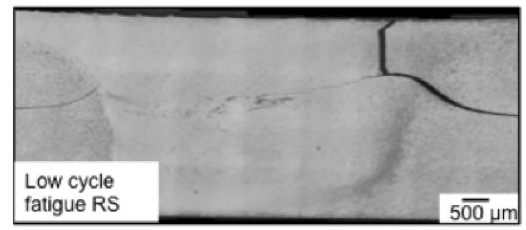

Fig. 15- a) Initial finite element mesh with boundary conditions of the advancing side loaded coupon. b) Deformed mesh after crack propagation and c) comparison to experimental observation of advancing side. d) Initial finite element mesh with boundary conditions of retreating side loaded coupon. e) Deformed mesh after crack propagation and f) comparison to experimental observation of retreating side.

Once the stress intensity factors were determined as a function of crack extension, the Paris model was applied to estimate fatigue life for the AS and RS stacking 
orientation for comparison to the experimental results. Since we assume a negligible crack initiation stage, the use of a crack growth model for predicting the number of cycles to failure for the FSLW lap-joint seems reasonable. Furthermore, a straightforward Paris type approach will help clarify the underlining relationship of the AS and RS configuration in fatigue and would be likely more difficult using a fatigue model with more input variables. The Paris law equation is shown in equation (1)

$$
\frac{d a}{d N}=C(\Delta K)^{m}
$$

where $a$ is the crack length, $N$ is the number of cycles, da/dN is the crack growth rate in $\mathrm{mm} /$ cycle, $\Delta K$ is the stress intensity factor range, and $C$ and $m$ are material constants, assumed to be $\mathrm{C}=4.2 \times 10^{-7} \frac{\mathrm{mm} / \mathrm{cycle}}{(M P a \sqrt{m})^{m}}$ and $\mathrm{m}=3.3[18]$.

Since in this study we calculated the stress intensity factor corresponding to crack length for each step (i.e. crack increment), it is possible to calculate the number of cycles necessary to grow the crack up to any step by rearranging equation (1) into the following:

$$
N_{i}=\sum_{0}^{i} \frac{\left(a_{i}-a_{i-1}\right)}{C\left[\left(K_{i}-K_{i-1}\right) / 2\right]^{m}}
$$

where $i$ is the crack increment, and $K$ is the stress intensity factor. 
Fig. 16- Comparison of the experimental fatigue results to the calculated number of cycle to failure of the AS and RS orientated FSLW coupons. The load ratio was R=0.1.

Figure 16 shows the comparison between the experimental results and the estimated fatigue life obtained from equation (2), where $i=43$ for the RS and $i=45$ for the AS. It is important to note that the number of cycles was not calculated for the run-out loads, since it is assumed these loads are in the threshold regime, where the fatigue cracks effectively do not propagate. However, we acknowledge that this assumption may be too broad and more advanced fatigue models would provide more accurate results.

While we observed very good correlations between the experimental results and the predicted number of cycles for the low cycle fatigue samples where we assumed mode I propagation, in the high cycle regime, the assumption of mode I may not be completely accurate. As noted earlier, the samples in the high cycle fatigue regime, as 
shown in Fig. 10, appear to propagate in a mixed-mode (I+II) as apposed to clearly mode I for the low cycle fatigue samples shown in Fig. 9. This appears to be likely due to the cracks taking the path of least resistance, which in the case of the high cycle fatigue is the boundary between the SZ and the TMZ. Since the driving force is lower in the high cycle regime, the fact that fatigue cracks propagated away from the preferred Mode I seems reasonable. In addition, this lower driving force also resulted in multi-crack propagation, which was observed in Figure 10. We further acknowledge that including a mixed-mode approach in the fatigue calculation would likely enhance the high cycle fatigue predictions and is the focus of future work.

Another possible source of error between the model and experimental results is related to the use of the BM fatigue crack growth material properties. In fact, this is one of the major drawbacks to using a crack growth approach for friction stir welded joints since the $\mathrm{C}$ and $\mathrm{M}$ parameters are usually not known. To the best of our knowledge, we are not aware of any literature that measured the $\mathrm{C}$ and $\mathrm{M}$ values of $\mathrm{AZ} 31 \mathrm{Mg}$ alloys. As such, we have assumed, as other have, that the $\mathrm{C}$ and $\mathrm{M}$ for the base materials are similar to the stir zone and valid for use in the calculation of number of cycles to failure. However, since we were interested in the comparison between the AS and RS and thus testing the hypothesis that macro features of the weld have a large influence on mechanical behavior, any error from not using $\mathrm{C}$ and $\mathrm{M}$ values from FSW data is identically applied to both orientations.

In general, the fatigue calculations coupled with experimental results reveal that fatigue lives of FSLW coupons are mostly dependent on macro features associated with 
the hooking and cold-lap features and less dependent on the variation in the microstructure of the weld features.

\section{Conclusions}

A study on the effect of stacking orientation on fatigue mechanisms in FSLW of AZ31

Mg alloy was performed. The following summary is presented:

1. Metallographic analysis was performed on the FSLW AZ31 Mg alloy with the purpose of characterizing the grain size and texture of untested coupons. The EBSD results showed high texture for the base material and the stir zone, while having similar grain morphologies.

2. Hardness measurements were carried out to determine the variation across the weld. The hardness measurements suggest similar microstructure at the advancing side hook and retreating side cold-lap feature.

3. Results of mechanical testing revealed that the retreating side orientated lap-joint exhibited superior static strength compared to the advancing side (an increase higher than 50\%) and fatigue life (up to an order of magnitude). Normalizing the experimental fatigue results by the ultimate strength of the lap-joint collapsed the fatigue curves. The correlation of the fatigue behavior to the ultimate strength suggests that one need only carry out fatigue tests for one of the orientations if the static strength of both are known.

4. Linear elastic fracture mechanic (LEFM) was used to predict the fatigue life of the advancing and retreating side orientated lap-joints. In fact, the fracture mechanics approach used in this paper was basically a blind calculation (no fine 
tuning parameters) that was very accurate in correlating the difference in the number of cycles to failure for both orientations. The results of the fracture mechanics approach for modeling the fatigue life of the lap-joint suggests that the difference in observed performance is strongly related to the geometrical features of the advancing and retreating side of the friction stir linear weld.

\section{References}

[1] I. R. Barnes, T. A., and Pashby, "Joining Techniques for Aluminum Spaceframes Used in Automobiles Part II-Adhesive Bonding and Mechanical Fasteners," $J$. Mater. Process. Technol., vol. 99, pp. 72-79, 2000.

[2] J. Yan, Z. Xu, Z. Li, L. Li, and S. Yang, "Microstructure characteristics and performance of dissimilar welds between magnesium alloy and aluminum formed by friction stirring," Scr. Mater., vol. 53, pp. 585-589, 2005.

[3] F. Czerwinski, "Welding and Joining of Magnesium Alloys," in Magnesium Alloys - Design, Processing and Properties, F. Czerwinski, Ed. Intech, 2011, pp. 469491.

[4] H. M. Rao, J. B. Jordon, M. E. Barkey, Y. B. Guo, X. Su, and H. Badarinarayan, "Influence of structural integrity on fatigue behavior of friction stir spot welded AZ31 Mg alloy," Materials Science \& Engineering A, vol. 564, pp. 369-380, 2013.

[5] B. T. Gibson, D. H. Lammlein, T. J. Prater, W. R. Longhurst, C. D. Cox, M. C. Ballun, K. J. Dharmaraj, G. E. Cook, and A. M. Strauss, "Friction stir welding: Process , automation , and control," Journal of Manufacturing Processes, vol. 16, no. 1, pp. 56-73, 2014.

[6] Q. Yang, X. Li, K. Chen, and Y. J. Shi, "Effect of tool geometry and process condition on static strength of a magnesium friction stir lap linear weld," Mater. Sci. Eng. A, vol. 528, pp. 2463-2478, 2011.

[7] M. K. Yadava, R. S. Mishra, Y. L. Chen, B. Carlson, and G. J. Grant, "Study of friction stir joining of thin aluminium sheets in lap joint configuration," Sci. Technol. Weld. Join., vol. 15, no. 1, pp. 70-76, 2010.

[8] W. Yuan, B. Carlson, R. Verma, and R. Szymanski, "Study of top sheet thinning during friction stir lap welding of AZ31 magnesium alloy," Sci. Technol. Weld. Join., vol. 17, no. 5, pp. 375-381, 2012.

[9] R. S. Mishra and Z. Y. Ma, "Friction stir welding and processing," Mater. Sci. Eng., vol. 50, pp. 1-78, 2005.

[10] L. Commin, M. Dumont, J.-E. Masse, and L. Barrallier, "Friction stir welding of 
AZ31 magnesium alloy rolled sheets: Influence of processing parameters," Acta Materialia, vol. 57, no. 2, pp. 326-334, Jan. 2009.

[11] M. Lugo, J. B. Jordon, K. N. Solanki, L. G. H. Jr, J. D. Bernard, A. A. Luo, and M. F. Horstemeyer, "Internati onal Journ al of Fatigue Role of different material processing methods on the fatigue behavior of an AZ31 magnesium alloy," International Journal of Fatigue, vol. 52, pp. 131-143, 2013.

[12] J. B. Jordon, M. F. Horstemeyer, S. R. Daniewicz, H. Badarinarayan, and J. Grantham, "Fatigue Characterization and Modeling of Friction Stir Spot Welds in Magnesium AZ31 Alloy," Journal of Engineering Materials and Technology, vol. 132, no. 4, p. 41008, Sep. 2010.

[13] N. Afrin, D. L. Chen, X. Cao, and M. Jahazi, "Microstructure and tensile properties of friction stir welded AZ31B magnesium alloy," Materials Science and Engineering: A, vol. 472, no. 1-2, pp. 179-186, Jan. 2008.

[14] H. N. B. Schmidt, T. L. Dickerson, and J. H. Hattel, "Material flow in butt friction stir welds in AA2024-T3," Acta Materialia, vol. 54, no. 4, pp. 1199-1209, Feb. 2006.

[15] K. Colligan, "Material flow behavior during friction welding of aluminum," Welding Journal, vol. 78, no. July, p. 229s-237s, 1999.

[16] T. U. Seidel and A. P. Reynolds, "Visualization of the material flow in AA2195 friction-stir welds using a marker insert technique," Metallurgical and Materials Transactions A, vol. 32, no. 11, pp. 2879-2884, 2001.

[17] H. M. Rao, J. B. Jordon, B. Ghaffari, X. Su, A. K. Khosrovaneh, M. E. Barkey, W. Yuan, and M. Guo, "Fatigue and fracture of friction stir linear welded dissimilar aluminum-to-magnesium alloys," vol. 82, pp. 737-747, 2016.

[18] K. Tokaji, M. Kamakura, Y. Ishiizumi, and N. Hasegawa, "Fatigue behaviour and fracture mechanism of a rolled AZ31 magnesium alloy," International Journal of Fatigue, vol. 26, no. 11, pp. 1217-1224, 2004. 